\section{Cureus}

\title{
Ultrasound Imaging in Radiation Therapy: From Interfractional to Intrafractional Guidance
}

\author{
Craig Western ${ }^{1}$, Dimitre Hristov ${ }^{2}$, Jeffrey Schlosser ${ }^{3}$ \\ 1. Department of Mechanical Engineering, Stanford University 2. Department of Radiation Oncology, \\ Stanford University 3. Founder, SoniTrack Systems
}

$\square$ Corresponding author: Jeffrey Schlosser, jeff@sonitracksystems.com Disclosures can be found in Additional Information at the end of the article

\section{Abstract}

External beam radiation therapy (EBRT) is included in the treatment regimen of the majority of cancer patients. With the proliferation of hypofractionated radiotherapy treatment regimens, such as stereotactic body radiation therapy (SBRT), interfractional and intrafractional imaging technologies are becoming increasingly critical to ensure safe and effective treatment delivery. Ultrasound (US)-based image guidance systems offer real-time, markerless, volumetric imaging with excellent soft tissue contrast, overcoming the limitations of traditional X-ray or computed tomography (CT)-based guidance for abdominal and pelvic cancer sites, such as the liver and prostate. Interfractional US guidance systems have been commercially adopted for patient positioning but suffer from systematic positioning errors induced by probe pressure. More recently, several research groups have introduced concepts for intrafractional US guidance systems leveraging robotic probe placement technology and real-time soft tissue tracking software. This paper reviews various commercial and research-level US guidance systems used in radiation therapy, with an emphasis on hardware and software technologies that enable the deployment of US imaging within the radiotherapy environment and workflow. Previously unpublished material on tissue tracking systems and robotic probe manipulators under development by our group is also included.

Received 02/26/2015

Review began $02 / 27 / 2015$ Review ended 05/25/2015 Published 06/20/2015

\section{(C) Copyright 2015}

Western et al. This is an open access article distributed under the terms of the Creative Commons Attribution License CC-BY 3.0., which permits unrestricted use, distribution, and reproduction in any medium, provided the original author and source are credited.
Categories: Medical Physics, Radiation Oncology

Keywords: ultrasound, robotics, image guidance, image-guided therapy, real-time system, treatment planning, liver cancer, prostate cancer, image-guided radiation therapy

\section{Introduction And Background}

External beam radiation therapy (EBRT) is used to treat $>60 \%$ of all cancer patients. Potent radiation doses with minimal treatment margins must be delivered in EBRT to maximize local tumor control and minimize toxicity to surrounding healthy tissue [1-3], but internal anatomy motion and deformation pose a fundamental threat to realizing these objectives. With the proliferation of hypofractionated radiotherapy treatment regimens, such as stereotactic body radiation therapy (SBRT), interfractional and intrafractional imaging technologies are becoming increasingly critical to ensure safe and effective treatment delivery [3-12].

The current gold standard for tumor motion management is X-ray imaging of implanted fiducial markers [13-16]. However, limitations, including marker migration [17-20], additional ionizing radiation exposure, implantation obstacles and morbidity [18-22], and the lack of volumetric information [17, 23-24], limit its utility. Cone-beam computed tomography (CBCT) produces a volumetric image of the patient's anatomy prior to treatment but cannot be used to 


\section{Cureus}

obtain intrafractional motion information [25]. Electromagnetic marker tracking enables realtime radiation-free motion tracking [26-28], but markers produce severe artifacts when used with computed tomography (CT) and magnetic resonance imaging (MRI) and do not yield volumetric images. Recent attempts at real-time, volumetric, markerless tracking for radiotherapy include using MRI and positron emission tomography (PET), but these approaches require the construction of new therapy machines with integrated imaging capabilities [29-31].

Ultrasound (US) offers an attractive alternative to the previously described approaches for imaging EBRT targets outside the skull and lung. Commonly used for image guidance in brachytherapy (robotic [32] and non-robotic [33]), biopsy [34], and other medical procedures, US imaging systems offer nonionizing, real-time volumetric imaging with excellent soft-tissue contrast. This paper describes various commercial and research-level US EBRT guidance systems, with specific emphasis on hardware and software technologies that enable the deployment of US imaging within the EBRT environment and workflow. Section 1 describes commercial interfractional US imaging systems, while Sections 2, 3, and 4 outline the various technical aspects of newer intrafractional US guidance systems, including static and robotic probe fixtures (Section 2), automatic tissue tracking software (Section 3), and treatment planning and spatial probe tracking sub-systems (Section 4). Previously unpublished material on tissue tracking systems and robotic probe manipulators under development by our group is included in Sections 2 and 3.

\section{Review}

\section{Interfractional US guidance}

The first applications of US in radiotherapy utilized US to image anatomy prior to treatment and inform patient placement relative to the linear accelerator (LINAC).

\subsection{BAT and SonArray Systems}

The first widely adopted US systems for interfractional imaging were the B-Mode Acquisition and Targeting (BAT) system (NOMOS Corp., Cranberry Township, PA) (Figure 1A), introduced in the United States markets in the late 1990s, and the SonArray system (Varian Medical Systems, Palo Alto, CA), introduced in the years following [35]. These systems use a 2D diagnostic US imaging system (refer to Section 4.1) and an optical or mechanical means (refer to Section 4.2) for tracking the position of the US probe with respect to the LINAC. In the BAT system, transabdominal US is used to image the target region in two near-orthogonal planes [36]. In the SonArray system, a sonographer sweeps the US probe across the target anatomy, capturing a series of $2 \mathrm{D}$ slices that are reconstructed into a 3D volume based on the relative slice positions. In both systems, the patient is positioned with respect to the LINAC prior to beam delivery by matching the planning CT volume to US images spatially localized in the LINAC frame [36-39].

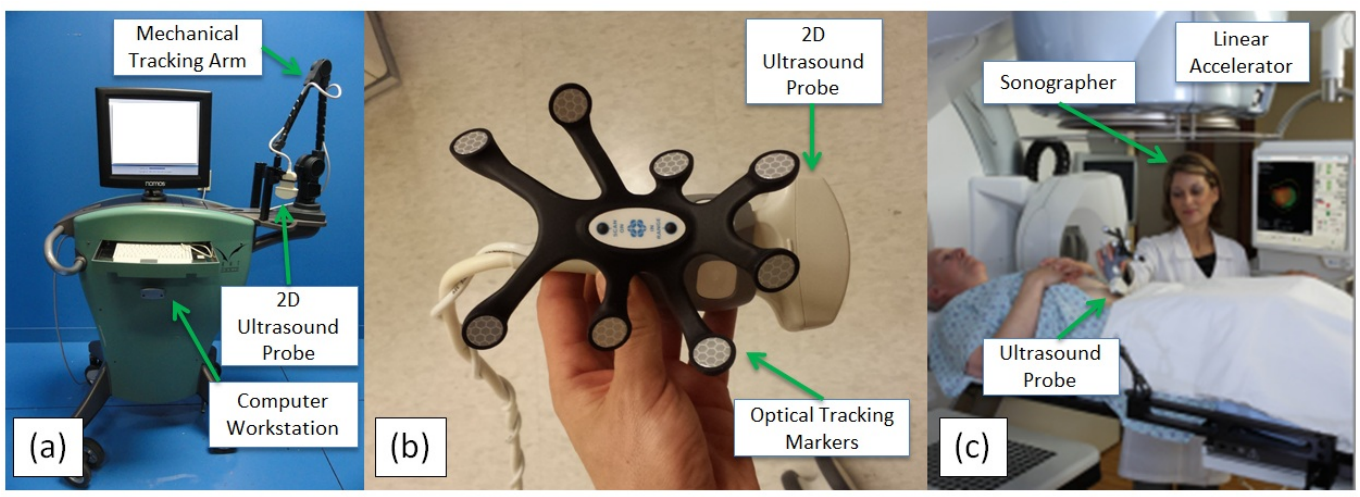


FIGURE 1: Interfractional US guidance systems.

(a) NOMOS B-mode Acquisition and Targeting (BAT), courtesy of Medicka Medical LLC. (b) Elekta Clarity probe. (c) Clarity probe in use, courtesy of Elekta, Inc.

When the BAT system arrived on the market, US was the only method for obtaining soft-tissue interfractional images (CBCT was not introduced until 1996 in Europe and 2001 in the United States) [40]. Little, et al. [38] found that without orthogonal plane US imaging, prostate motion would have caused the target to move outside of the planning target volume (PTV) in $23.3 \%$ to $41.8 \%$ of cases, concluding also that prostate organ motion dominates setup error. Studies of patients with prostate cancer by Lattanzi, et al. [36] demonstrated that alignment errors between a baseline CT and US after initial positioning often exceeded $5 \mathrm{~mm}$ using the BAT system, with maximum ranges of -26.8 to $33.8 \mathrm{~mm}$ in the anteroposterior (AP) direction, -10.2 to $30.9 \mathrm{~mm}$ in the mediolateral (ML) direction, and -24.6 to $9.0 \mathrm{~mm}$ in the superoinferior (SI) dimension. Boda-Heggemann, et al. [39] found that the BAT system improved positioning accuracy when compared to positioning using bony anatomy in CBCT scans and significantly improved positioning accuracy over skin marks (with magnitudes of residual error relative to positioning based on skin marks between 2.1 and $5.2 \mathrm{~mm}$ ).

Several studies have compared BAT and SonArray positioning accuracy with X-ray fiducial marker positioning. Langen, et al. [41] showed that prostate alignment using the BAT system systematically differs from alignment using radiographic fiducial marker imaging in the SI (2.7 \pm $3.9 \mathrm{~mm})$ and $\mathrm{ML}(1.6 \pm 3.1 \mathrm{~mm})$ directions, but differences were minimal in the AP direction $(0.2 \pm 3.7 \mathrm{~mm})$. Van den Heuvel, et al. [42] found that position shifts suggested by the BAT system were similar to fiducial marker shifts in the AP and ML directions but differed significantly in the SI direction, suspecting a systematic error in their BAT positioning system. Peignaux, et al. [43] found significant differences in SonArray vs. X-ray fiducial marker positioning along the SI and AP axes. Scarbrough, et al. [44] found a three-dimensional distance discrepancy between the two methods of $8.8 \mathrm{~mm}$ (significantly $>5 \mathrm{~mm}$ ), concluding that larger target volume margins are necessary for SonArray (approximately $9 \mathrm{~mm}$ ) as compared with $\mathrm{kV}$ X-ray (approximately $3 \mathrm{~mm}$ ) in intrafractional imaging applications.

Although initial studies of the BAT and SonArray systems demonstrated the promise of improved soft tissue-based prostate positioning, cross-examination with X-ray fiducial imaging revealed systematic biases. Reliance on intermodality matching of US and CT image information is partially responsible for these systematic errors. For example, prostate volumes derived from CT scans are consistently larger than those derived from US images because of differing physical image contrast mechanisms and the inability of CT to differentiate structures well at low contrast [35]. Molloy, et al. [45] estimated prostate size differences to be up to $9 \mathrm{~mm}$ in the ML direction and $3 \mathrm{~mm}$ in the AP direction. Cury, et al. [46] showed systematic differences in intermodality and intramodality positioning, finding significant mean differences of $0.9 \pm 3.3 \mathrm{~mm}$ in the ML and $6.0 \pm 5.1 \mathrm{~mm}$ in the SI directions between the two techniques. Because a comparison of intramodality US imaging and CT scans showed no significant differences in any direction, it was concluded that intramodality-based positioning is more accurate than intermodality positioning. Therefore, intramodality image matching has been recommended to minimize patient positioning error in US-guided radiotherapy [35].

\subsection{Clarity System}

The Clarity System (Figure 1B-C) (Elekta AB, Stockholm, Sweden) leverages intramodality image matching instead of the intermodality matching technique used by BAT and SonArray. 
Intramodality matching is achieved by capturing a US volume directly before or after the planning CT scan. By tracking the precise position and orientation of the US probe with respect to the CT scanner, the 3D US volume can be reconstructed in the reference frame of the CT. Directly prior to treatment, a new 3D US volume is captured in the LINAC room and reconstructed with respect to the LINAC reference frame. To position the patient, the US volumes collected during planning and prior to treatment are matched and used to determine patient anatomy offset relative to the desired planning position [47]. Since intramodality image matching has been shown to improve accuracy over intermodality matching as described in Section 1.1, the Clarity system should theoretically position patients more accurately than the BAT system or SonArray system.

Gurp, et al. [48] demonstrated feasibility of US-based image guidance in SBRT of liver lesions using the Clarity system, finding that the variability of image segmentation in scanned images was $4 \mathrm{~mm}$ (one standard deviation), and could be reduced by $1.7 \mathrm{~mm}$ in the SI direction using active breathing control. To evaluate the error in the Clarity system applied to breast imaging, Wong, et al. [49] compared CT scans of breast cancer patients taken just before radiation to Clarity US images taken at corresponding times. The difference between CT and US images of the tumor bed centroid position averaged $0.1 \pm 2.8 \mathrm{~mm},-0.2 \pm 4.0 \mathrm{~mm}$, and $0.4 \pm 3.7 \mathrm{~mm}$ in the AP, LR, and SI directions, respectively, which was deemed clinically insignificant. Robinson, et al. [50] found the prostate positioning error between Clarity scans and CT scans compared to a reference scan to be significant, observing a discrepancy of $5 \mathrm{~mm}$ or more between CT and US localizations in $>80 \%$ of cases despite expert re-analysis of data.

While the Clarity System leverages intramodality image matching, an improvement relative to the intermodality matching used by the BAT and SonArray systems, conflicting reports of Clarity's positioning accuracy bring to light the shared shortcomings of interfractional US image guidance systems:

1. Pressure applied by the US transducer on the patient's body can cause anatomy deformations and displacements of varying magnitude, depending on the properties and depth of the treatment target. Since pressure applied during pre-treatment imaging is not present during beam delivery, systematic positioning errors are common [51-53].

2. The quality and consistency of freehand US-based patient alignment is significantly dependent on the operator and level of training [41, 54].

3. The Clarity and BAT systems rely on freehand probe manipulation, which would pose an unacceptable hazard to the probe operator if performed during treatment delivery. Thus, no imaging is available during beam delivery when accurate target tracking is most critical.

\section{Intrafractional US guidance: Image acquisition devices}

Intrafractional US guidance systems are the next step in the evolution of US imaging for radiotherapy, providing real-time, volumetric, markerless target tracking concurrent with beam delivery in packages that integrate with existing LINACs. The foundation of an intrafractional US guidance system is a hardware device to maintain the US probe in imaging position during therapy while the sonographer is outside the treatment room. The device must hold the probe in a way that maintains the therapy target within the US imaging field of view throughout treatment while minimizing possible interference with the LINAC, the patient's body, and treatment beams. This section describes several intrafractional US image acquisition devices currently in clinical use or in development.

\subsection{Static Devices}




\section{Cureus}

The first US guidance system capable of intrafractional imaging was the Clarity Autoscan System (Elekta AB, Stockholm, Sweden), shown in Figure 2A. The Clarity Autoscan builds upon the original Clarity System (Section 1.2) by replacing the 2D US imaging system with a mechanical "wobbler" 3D/4D US imaging system (refer to Section 4.1) and adding a hardware fixture for hands-free transperineal prostate imaging. The hardware device is a simple, manually-operated 5-degree of freedom (DOF) fixture that is mounted to a plate on the treatment couch between the patient's legs. The sonographer uses the fixture to lock the US probe into position after the initial transperineal imaging position is found, thus freeing the sonographer to exit the treatment room and deliver radiotherapy while the US probe remains in imaging position. The 3D/4D probe enables volumetric US images to be automatically captured without physically moving the US probe head. The transperineal imaging setup is advantageous because the geometry of the fixture and probe keeps all system hardware out of the normal delivery plane for C-arm LINACs, therefore avoiding guidance system hardware interference with the radiation treatment process and enabling simultaneous US/CT imaging during the radiotherapy planning phase. Clinical studies of the system are underway to characterize the performance of the Clarity Autoscan for intrafractional monitoring.

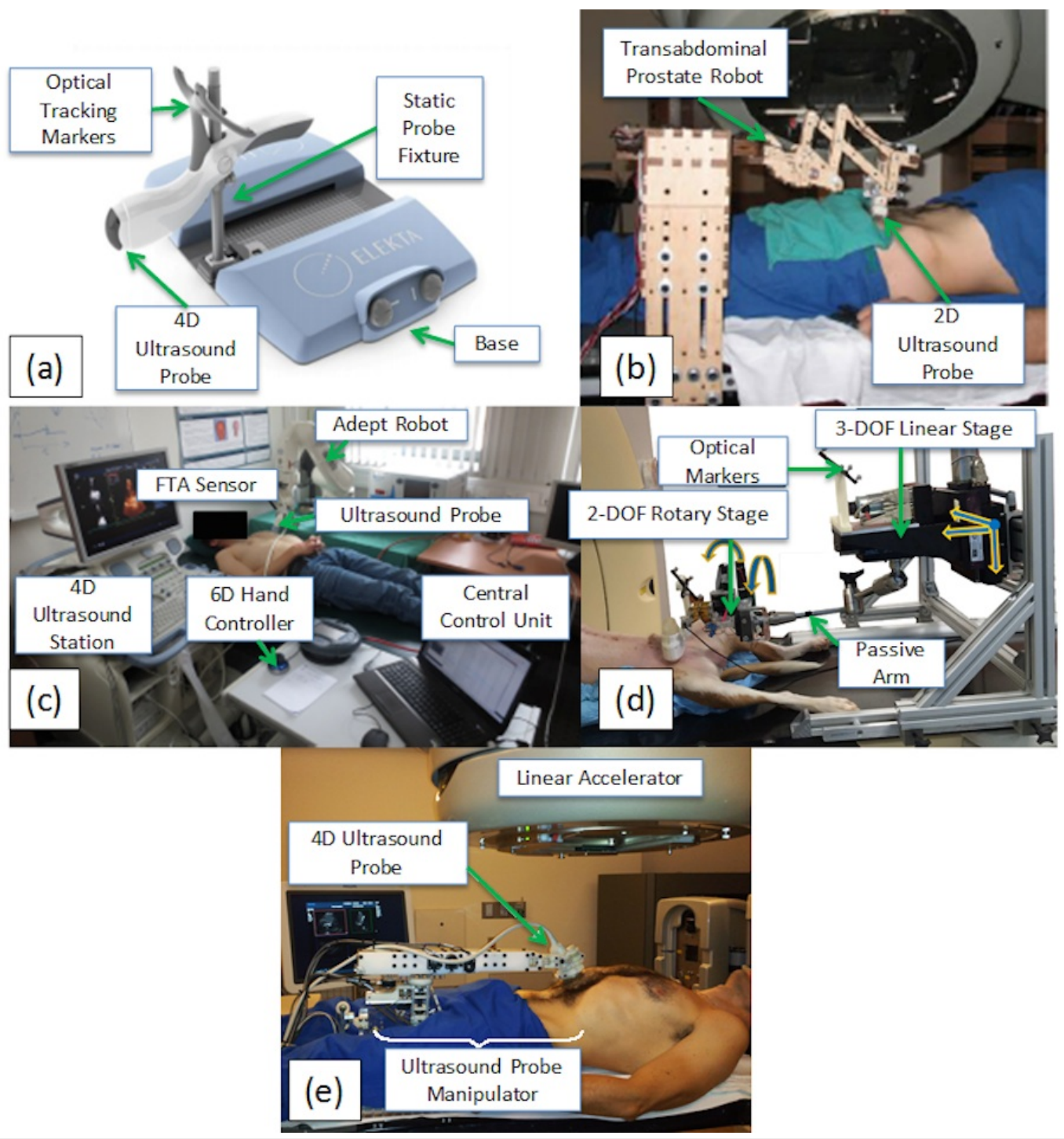

\section{FIGURE 2: Devices to support intrafractional US imaging.}

(a) Clarity Autoscan system, reproduced from Lachaine and Falco[47]. (b) Stanford prostate imaging robot, reproduced from Schlosser et al.[58] (c) University of Lubeck robot, adapted from Kuhlemann[59]. (d) Johns Hopkins robot, adapted from Sen et al.[61] (e) Stanford abdominal 


\subsection{Robotic Devices}

This section describes four actively-controlled (robotic) devices under development by academic institutions for maintaining probe positioning against the patient during beam delivery. Robotic ultrasound systems have been investigated in the past for diagnostic imaging purposes [55-57], but such systems are inadequate for image guidance in radiotherapy because the kinematics, workspace, and design features do not comply with the geometric and workflow constraints of the radiotherapy environment.

\subsubsection{Stanford Prostate Imaging Robot}

Schlosser, et. al. [58] were the first to demonstrate the feasibility of robotic intrafractional US imaging in the context of radiotherapy guidance. As a proof-of-concept, they developed and evaluated a robotic device designed for controlling 2D transabdominal US imaging of the prostate, shown in Figure $2 B$. The device has two active degrees of freedom for controlling probe pitch (tilt in the superior/inferior direction) and pressure against the abdomen, and three passive, mechanically locking degrees of freedom for manually setting probe position prior to the procedure. The active degrees of freedom can be remotely controlled during beam delivery using a joystick with force feedback known as a haptic device. With the telerobotic system, the authors demonstrated that gantry collisions are avoidable, stable remotely-controlled prostate imaging is achievable in healthy human subjects over 10-minute time periods, and robotic performance is not degraded during operation of a $15 \mathrm{MV}$ radiation beam.

\subsubsection{University of Lubeck Robotic Platform}

The University of Lubeck has developed a robotic US probe positioning system for CyberKnife radiotherapy using an off-the-shelf robotic arm (Viper S850, Adept Technology, Inc.) shown in Figure $2 C$ [59]. The robot has six actively-controlled degrees of freedom (DOF), enabling probe placement on nearly any part of the patient's body. User commands controlling robot pose are input using a 6-DOF hand controller/computer interface and sent via TCP/ IP protocol to the control software [60]. Continuous high-quality imaging was confirmed by showing that image structure/entropy stayed above the threshold for continuous target tracking of heart volumes at least $95 \%$ of the time in three healthy human subjects over 30-minute time intervals [59]. An updated version of the system uses a KUKA (Augsburg, Germany) 7-axis lightweight robot with integrated force control. In addition to manual 6-DOF positioning, force- and image-based positioning strategies have been developed.

\subsubsection{Johns Hopkins Abdominal Imaging Robot}

Sen, et al. [61] have developed a custom-designed robotic manipulator, shown in Figure 2D, for US-guided radiotherapy with particular focus on overcoming inconsistencies in tumor localization between the planning and treatment phases due to tissue deformation induced by probe pressure. The design incorporates a six-axis force/torque sensor for force feedback, five active degrees of freedom (three translational and two rotational-probe spin is not actively regulated), seven passive degrees of freedom, and optical robotic position tracking. In the CT planning phase, a model probe containing no metallic components is positioned against the abdomen to cause deformation similar to that which occurs during treatment. During the treatment setup phase, a virtual spring system helps the ultrasonographer manually move the probe to a position similar to that recorded during planning, inducing repeatable deformation 
and repeatable force. Virtual springs consist of motors in the robotic joints that exert force toward the position recorded during planning. Flexibility in the virtual springs accommodates any changes in position that the sonographer deems necessary. Treatment planning is carried out with the model probe, which is penetrable by X-rays, held in position, such that a CT scan can be conducted. In ex vivo experiments using a bovine liver fixed in gelatin with implanted fiducials, the system demonstrated repeatable arm placement with minimal effect on displacement of the fiducials, yielding (after six repeated arm placements) a mean absolute difference between fiducial displacements of $0.4 \pm 0.4 \mathrm{~mm}$ in US images and $0.3 \pm 0.2 \mathrm{~mm}$ in CT images acquired with the model probe [62]. Later in vivo experiments conducted on a dog demonstrated mean 3D reproducibility of 0.6 to $0.7 \mathrm{~mm}, 0.3$ to $0.6 \mathrm{~mm}$, and 1.1 to $1.6 \mathrm{~mm}$ for the prostate, liver, and pancreas, respectively, under position control and controlled ventilation [53]. Force control proved less reproducible, however, indicating that position control rather than force control should be used for robotic substitution of real and model probes. Results indicated that the system shows promise for monitoring real-time organ motion, particularly under conditions of minimal probe pressure.

\subsubsection{Stanford Abdominal Imaging Robot}

Our research group at Stanford, in collaboration with SoniTrack Systems, Inc., has developed a second-generation custom-designed robotic device based on learnings from our first proof-ofconcept prototype (Section 2.2.1), shown in Figure 2E. The goal of the research effort is to produce a simple, compact, human-safe robotic design that enables 3D/4D US imaging of any abdominal radiotherapy target, actively controls probe force, allows rapid and repeatable positioning of the US probe, and eliminates metal in areas exposed to CT/therapy radiation. The resulting design has a single active DOF to control probe pressure against the patient, five passive, electronically locking probe positioning DOFs, and three passive, manually actuated positioning DOFs [63]. The active DOF is controlled with a series elastic force controller that has the following advantages: (1) easy back driveability in case of power failure; (2) elimination of the need for a metallic force sensor near the US probe; and (3) inherent safety when used to control contact with human subjects. Metallic components of the robotic arm in the CT/therapy field are eliminated by coupling the 3-DOF robot wrist with remotely located sensors and actuators via a mechanical cable drive system. The 9-DOF robot design enables easy access to any abdominal target on the patient's body while accommodating a wide range of patient body shapes and avoiding potential collisions with the rotating LINAC. The robot has demonstrated successful imaging over extended time periods on the prostate, pancreas, liver, and kidneys of healthy volunteers under informed consent.

\subsubsection{Comparison}

Table 1 compares the previously described static and robotic intrafractional US image acquisition systems. While static systems, such as the Clarity Autoscan, currently represent state-of-the-art clinically deployed US guidance for radiation therapy, robotic systems still in development can overcome limitations fundamental to static assemblies. While static fixtures for transperineal imaging do not interfere with radiation beams and eliminate CT scanning artifacts within the anatomy of interest, transperineal imaging is limited to the prostate as other major radiotherapy target organs cannot be reached. The Stanford prostate robot and the Lubeck robot both improve upon this by adding force control, but because of incompatibility with CT, both are unable to maintain consistent probe force between the planning and treatment phases. The Johns Hopkins robot is able to reproduce anatomical positioning during CT and radiotherapy delivery using 5-DOF actuated robotic position and force control. The Stanford abdominal robot achieves CT compatibility, continuous force control, and natural US probe positioning in a lightweight, low-cost, human-safe package. 


\section{Cureus}

\begin{tabular}{|c|c|c|c|c|c|}
\hline & $\begin{array}{l}\text { Clarity } \\
\text { Autoscan[47] }\end{array}$ & Stanford prostate[58] & $\begin{array}{l}\text { Johns } \\
\text { Hopkins[61] }\end{array}$ & Lubeck[59] & $\begin{array}{l}\text { Stantord } \\
\text { Abdominal[63] }\end{array}$ \\
\hline $\begin{array}{l}\text { For use } \\
\text { with }\end{array}$ & 3D/4D US & 2D US & 3D/4D US & 3D/4D US & 3D/4D US \\
\hline Active DOF & 0 & 2 & 5 & $6 / 7$ & 1 \\
\hline $\begin{array}{l}\text { Passive } \\
\text { DOF }\end{array}$ & 5 & 3 & 7 & 0 & 8 \\
\hline $\begin{array}{l}\text { Probe force } \\
\text { control }\end{array}$ & None & $1 \mathrm{DOF}$ & $5 \mathrm{DOF}$ & 6 DOF & $1 \mathrm{DOF}$ \\
\hline compatible & Yes & No & Yes & No & Yes \\
\hline $\begin{array}{l}\text { Remote } \\
\text { control } \\
\text { interface }\end{array}$ & N/A & Haptic control & $\begin{array}{l}\text { Computer } \\
\text { interface }\end{array}$ & $\begin{array}{l}\text { 6D hand controller/ } \\
\text { Computer } \\
\text { interface }\end{array}$ & Computer interface \\
\hline $\begin{array}{l}\text { Organs } \\
\text { tested }\end{array}$ & $\begin{array}{l}\text { Human } \\
\text { subjects: } \\
\text { prostate }\end{array}$ & $\begin{array}{l}\text { Human subjects: } \\
\text { prostate, liver }\end{array}$ & $\begin{array}{l}\text { Canine: } \\
\text { Prostate, Liver, } \\
\text { Pancreas }\end{array}$ & $\begin{array}{l}\text { Human subjects: } \\
\text { Heart, Liver }\end{array}$ & $\begin{array}{l}\text { Human subjects: Liver, } \\
\text { kidney, prostate, } \\
\text { pancreas }\end{array}$ \\
\hline $\begin{array}{l}\text { Organs } \\
\text { compatible }\end{array}$ & $\begin{array}{l}\text { Prostate } \\
\text { (transperineal) }\end{array}$ & $\begin{array}{l}\text { Prostate } \\
\text { (transabdominal), liver } \\
\text { (in some cases) }\end{array}$ & $\begin{array}{l}\text { Abdominal, } \\
\text { pelvic }\end{array}$ & $\begin{array}{l}\text { Abdominal, pelvic, } \\
\text { thoracic }\end{array}$ & Abdominal, pelvic \\
\hline
\end{tabular}

TABLE 1: Comparison of intrafractional US image acquisition systems used in radiotherapy.

\section{Intrafractional US guidance: Automatic tissue tracking}

To enable intrafractional treatment intervention, US images collected during beam delivery must be processed in real-time to extract soft tissue motion information. Threedimensional/four-dimensional US imaging for intrafractional guidance maximizes information content in images and enables true 3D motion tracking but suffers from slower frame rates and longer image processing times when compared with 2D US imaging. While tissue tracking algorithms are employed in a range of medical applications, this section reviews methods implemented on 2D and 3D/4D US image streams for the specific purpose of intrafractional radiotherapy guidance.

\subsection{D Tissue Tracking}

To demonstrate early feasibility of 2D US in monitoring intrafractional soft-tissue displacements of the prostate, Schlosser, et al. [64] developed a method using two tissue displacement parameters (TDPs) derived from the normalized cross correlation similarity measure that characterized in-plane and out-of-plane displacement of the target volume in real time relative to a reference position. The method, used in conjunction with the robotic device described in Section 2.2.1, successfully detected prostate displacements in healthy 
human subjects before they exceeded 2.3, 2.5, and $2.8 \mathrm{~mm}$ in the AP, SI, and ML directions, respectively, at the $95 \%$ confidence level, with a total system latency averaging $173 \mathrm{~ms}$. False positives did not exceed 1.5 events over 10 minutes of continuous imaging. The authors performed an online demonstration of the system in which a healthy human subject was asked to physically move his hips at certain time intervals, causing a displacement of the prostate relative to a "world" reference frame. Hip displacements were monitored using an external marker on the volunteer's hip and with the 2D US-based TDPs. The TDPs detected 10 out of 10 prostate displacements and registered zero false positives over the 12-minute online test. Results of the test are illustrated in Figure 3.
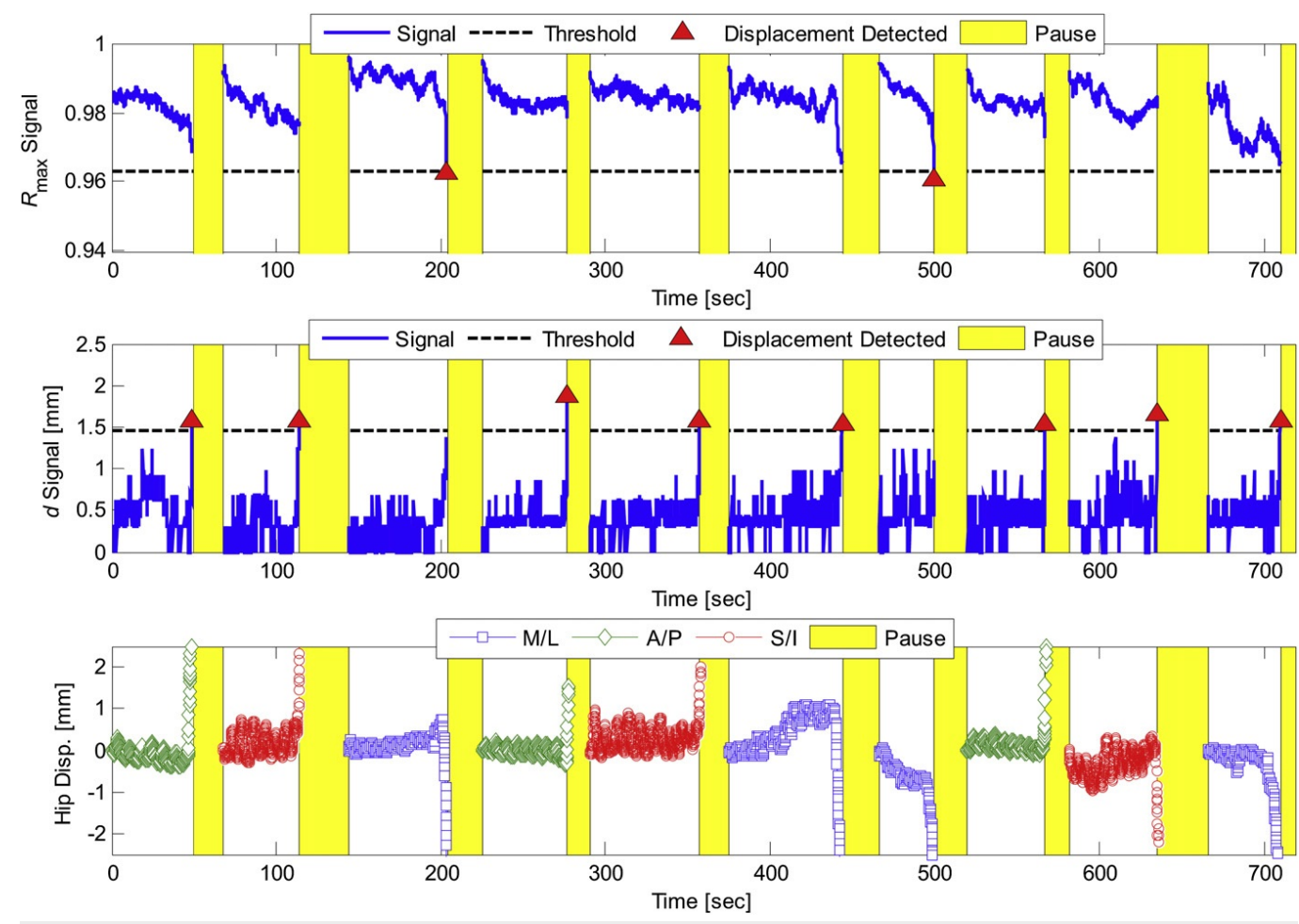

\section{FIGURE 3: Tissue displacement parameters (TDPs) during 12- min test session, reproduced from Schlosser et al.}

Tissue displacement parameters (TDPs) during 12-min test session, reproduced from Schlosser et al. [64] Triangles indicate which parameter detected the displacement. Shaded regions indicate the period after the detection in which tissue monitoring was paused, a new template window was selected, and the TDPs were reset. The bottom graph shows the position of the external marker on the volunteer's hip.

A similar demonstration of feasibility was carried out by Schlosser, et al. [65] using 2D US for monitoring the motion of the liver in healthy human subjects under informed consent. US image streams were acquired remotely in volunteers for 60-120 seconds using the robotic device described in Section 2.2.1. Concurrently, the position of an external infrared skin marker fixed to each subject's abdomen was tracked. Within each image stream, the displacement of two separate liver features was monitored using normalized cross correlation, one serving as a baseline "target" and the other one as an internal target surrogate. Two models were fitted and used to predict target motion. The first one used the displacement of the external marker surrogate as an input signal. The second one used the displacement of the 
internal US surrogate feature as an input. Discrepancies between the measured target positions and those predicted by the models were quantified. In a separate analysis, the Pearson correlation coefficient and phase difference between the surrogate signals and the target signal were examined as a function of time.

Errors based on the external surrogate model was larger than $2.0 \mathrm{~mm}$ on average, at times exceeding $4.0 \mathrm{~mm}$ while the mean error was less than $1.0 \mathrm{~mm}$ using the internal US surrogate model. Pearson correlation coefficient averaged 0.83 between external surrogate motion and target motion, in contrast to 0.97 between internal surrogate and target. The study thus demonstrated superior tracking of target motion using US to monitor the displacement of an internal feature when compared with tracking of an external surrogate. Results are illustrated in Figure 4.
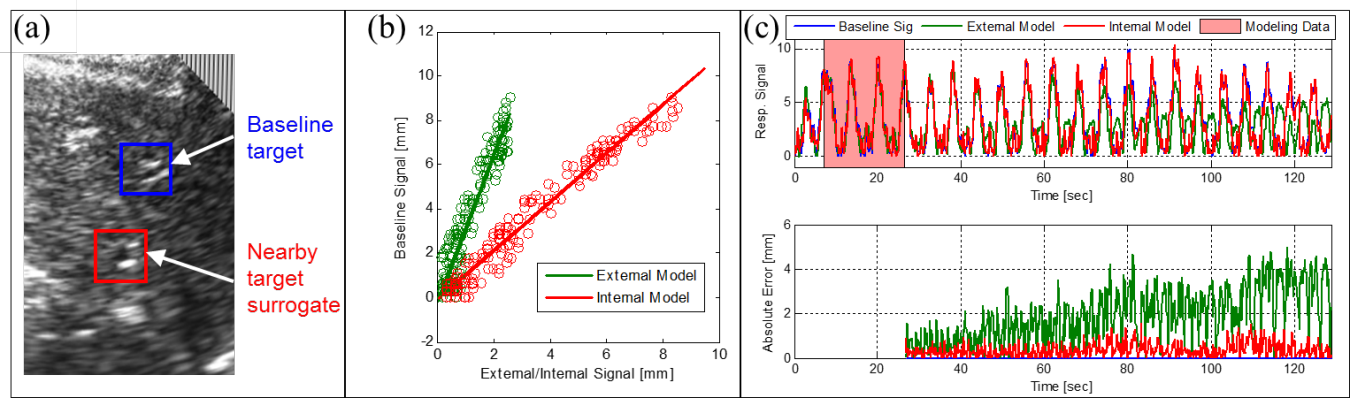

\section{FIGURE 4: Respiratory analysis for the liver.}

(a) Baseline blood vessel and nearby target. (b) Linear predictive models. (c) Respiratory signals and model errors. Reproduced from Schlosser[63]

\subsection{D/4D Tissue Tracking}

Harris, et al. [66] assessed tracking accuracy and precision of real-time 4D US using a mechanically swept probe on both a tissue-mimicking phantom and on liver motion of healthy volunteers in vivo. Using a 3D cross correlation-based tracking algorithm, results found nonincremental tracking (comparing each volume with the first volume) to be superior to incremental tracking (comparing each volume to the next) and good agreement between in vivo cases tracked automatically and manually, with $1.7 \mathrm{~mm}$ mean absolute distance of the difference between the two methods. Subsequent studies [67] conducted on liver motion in vivo examined the effect of volumetric imaging rates using a 4D matrix array US probe, finding that lower volume rates $(2-12 \mathrm{~Hz}$ ) resulted in root mean squared deviation (RMSD) values of 2-6 $\mathrm{mm}$ relative to the highest rates $(24 \mathrm{~Hz})$. In a third study, the accuracy of a mechanically-swept $4 \mathrm{D}$ US probe for transperineal monitoring of prostate motion was evaluated using a US phantom undergoing prescribed motion [68]. The system tracked SI and AP motion to $\leqslant 0.81$ mm RMS error at a $1.7 \mathrm{~Hz}$ volume rate as compared with $0.74 \mathrm{~mm}$ for the CyberKnife system to which volumetric US was being compared. The error was higher in the ML direction (elevational sweep direction for the US probe) but could be reduced to $\leqslant 2.0 \mathrm{~mm}$ using a correlational threshold.

The Clarity Autoscan System monitors intrafractional prostate motion by continuously gathering swept 2D slices of the region of interest in a cylindrical coordinate frame [47]. Rather than wait for a full 3D US sweep, 2D slices are registered in succession on each partially updated image using normalized cross correlation. The registration algorithm calculates a correlation score for each iteration, and if the correlation is below a threshold chosen based on 
training data, a displacement is suspected and the user is alerted to verify the registration. Lachaine and Falco [47] showed that the accuracy of the Clarity system is $-0.2 \pm 0.2 \mathrm{~mm}, 0.2 \pm$ $0.4 \mathrm{~mm}$, and $0.0 \pm 0.2 \mathrm{~mm}$ in the AP, LR, and SI directions, respectively, by comparing Clarity tracking of a phantom with motion patterns fed to a robotic stage. In a similar study, Abramowitz, et al. [69] showed 95\% of maximum distance variation between Clarity measurements and optical control measurements of a robotically controlled probe to be less than $1.3 \mathrm{~mm}$, with the majority less than $1 \mathrm{~mm}$. In both studies, target geometry and motion were informed by prostate motion profiles.

In the robotic system developed by Bruder, et al. [70], template matching algorithms using the sum of squared differences (SSD) are employed for the purpose of tissue tracking. Similar to previously described methods, the process involves the comparison between the current US volume and a template - a volume previously captured at a specific position. Unlike previously described rigid tracking algorithms, Bruder accounts for target deformation by developing a multi-template matching algorithm in which the current US volume is compared with a number of templates that represent snapshots of the patient's anatomy across a range of deformations - for example, through a single breathing cycle. The algorithm is successfully employed in the University of Lubeck robotic system (Section 2.2.2) with $15 \mathrm{~ms}$ of processing time in practice.

Kubota, et al. [71] have proposed a 3D tissue tracking algorithm for monitoring organs affected by respiratory motion. The algorithm first required manually identifying a region of interest that enveloped the target. A direction of maximum displacement due to respiratory motion was then identified prior to tracking by averaging images acquired at maximum inspiration and expiration. In tracking target motion in real-time, a Pyramidical Lucas-Kanade method was used to associate a large number of feature points in each frame with points in the previous frame, then moving the region of interest in a direction associated with the motion of these points. In order to adjust for deformations and stacked error over time, error correction was applied by comparing images at maximum inspiration and expiration over multiple cycles and updating, if necessary, under the assumption that target position in the image of maximum inspiration was constant between cycles. The method was validated by tracking the gallbladder in one subject and a liver vein in a second subject. The proposed algorithm was compared with a template matching algorithm and a second algorithm involving feature point tracking without error correction. The proposed algorithm outperformed both alternatives, allowing longer tracking times (up to 5 minutes) and consistent tracking through organ deformation and changes in cross-sectional position. Average tracking accuracy was $1.54 \pm 0.9 \mathrm{~mm}$, with accuracy defined as deviation from the center of the region of interest and the center of the target organ designated by an experienced medical doctor. Computation time was 8 ms per frame for 2000 frames processed.

Table 2 reviews the previously discussed tissue tracking systems. 


\section{Cureus}

\begin{tabular}{|c|c|c|c|c|c|c|}
\hline Study & Method & 2D/3D & $\begin{array}{l}\text { Temporal } \\
\text { Characteristics }\end{array}$ & Accuracy & $\begin{array}{l}\text { Organs } \\
\text { Tested }\end{array}$ & $\begin{array}{l}\text { Evaluated } \\
\text { In Vivo or } \\
\text { Phantom }\end{array}$ \\
\hline $\begin{array}{l}\text { Schlosser } \\
\text { et al. } \\
2012 \text { [64] }\end{array}$ & $\begin{array}{l}\text { Tissue displacement } \\
\text { parameters based on } \\
\text { 2D normalized cross- } \\
\text { correlation }\end{array}$ & $2 \mathrm{D}$ & $\begin{array}{l}173 \text { ms system } \\
\text { latency; } 9 \mathrm{~Hz} \\
\text { frame rate }\end{array}$ & $\begin{array}{l}<2.8 \mathrm{~mm} \text { at } 95 \% \\
\text { confidence }\end{array}$ & Prostate & In vivo \\
\hline $\begin{array}{l}\text { Schlosser } \\
\text { et al. } \\
2011 \text { [65] }\end{array}$ & $\begin{array}{l}\text { 2D normalized cross- } \\
\text { correlation }\end{array}$ & 2D & $\begin{array}{l}173 \text { ms system } \\
\text { latency; } 9 \mathrm{~Hz} \\
\text { frame rate }\end{array}$ & $<1 \mathrm{~mm}$ mean & Liver & In vivo \\
\hline $\begin{array}{l}\text { Harris et } \\
\text { al. } 2010 \\
{[66]}\end{array}$ & $\begin{array}{l}\text { Non-incremental 3D } \\
\text { cross correlation }\end{array}$ & $3 \mathrm{D}$ & Not reported & $1.7 \mathrm{~mm}$ in vivo & Liver & $\begin{array}{l}\text { In vivo, } \\
\text { phantom }\end{array}$ \\
\hline $\begin{array}{l}\text { O'Shea et } \\
\text { al. } 2014 \\
{[68]}\end{array}$ & $\begin{array}{l}\text { 3D cross-correlation } \\
\text { with block matching }\end{array}$ & $3 \mathrm{D}$ & 1.7 Hz frame rate & $\begin{array}{l}\leq 0.81 \mathrm{~mm} \text { in phantom } \\
\text { case, SI and AP } \\
\text { directions }\end{array}$ & N/A & Phantom \\
\hline $\begin{array}{l}\text { Clarity } \\
\text { Autoscan } \\
{[47,69]}\end{array}$ & $\begin{array}{l}\text { 2D/3D normalized } \\
\text { cross-correlation }\end{array}$ & $\begin{array}{l}2 \mathrm{D} / \\
3 \mathrm{D}\end{array}$ & $\begin{array}{l}0.5 \text { second sweep } \\
\text { time or greater } \\
\text { depending on } \\
\text { resolution }\end{array}$ & $\begin{array}{l}0.2 \pm 0.4 \mathrm{~mm} \text { worst-case } \\
\text { for AP, ML, and SI } \\
\text { directions (Lachaine); } 1.3 \\
\text { mm (Abramowitz) }\end{array}$ & N/A & Phantom \\
\hline $\begin{array}{l}\text { Bruder et } \\
\text { al. } 2009 \\
{[70]}\end{array}$ & $\begin{array}{l}\text { SSD and multi- } \\
\text { template matching }\end{array}$ & $3 \mathrm{D}$ & $\begin{array}{l}50 \text { ms system } \\
\text { latency; } 20 \mathrm{~Hz} \\
\text { frame rate }\end{array}$ & Not reported & Heart, liver & In vivo \\
\hline $\begin{array}{l}\text { Kubota et } \\
\text { al. } 2014 \\
{[71]}\end{array}$ & $\begin{array}{l}\text { Feature point tracking } \\
\text { with error correction } \\
\text { algorithm }\end{array}$ & $3 \mathrm{D}$ & $\begin{array}{l}8 \mathrm{~ms} \text { image } \\
\text { processing time }\end{array}$ & $1.54 \pm 0.9 \mathrm{~mm}$ & $\begin{array}{l}\text { Gallbladder, } \\
\text { liver vein }\end{array}$ & In vivo \\
\hline
\end{tabular}

TABLE 2: Comparison of US tissue tracking systems used in radiotherapy.

\section{Additional considerations for US-guided EBRT}

\subsection{US Imaging Probes}

In US imaging, acoustic waves are sent and received by a US probe coupled to a scanned volume of tissue. Variation in physical properties of the scanned volume causes a proportion of the outgoing acoustic energy to be reflected back to the probe. By recording the amplitude and timing of reflections and assuming a particular speed of sound, an image of the scanned volume can be reconstructed. Two-dimensional US probes propagate acoustic waves in a single plane within the patient's body, either using a single mechanically-steered transducer element, or more commonly, using a linear or curvilinear array of transducer elements [72]. In 3D/4D US probes, waves are propagated throughout a 3D volume of tissue (4D imaging refers to continuous real-time 3D imaging). A 3D/4D "wobbler" probe mechanically sweeps a linear or curvilinear array of transducers to collect multiple 2D planes within a volume region of interest 
[73], while a matrix array 3D/4D probe uses a 2D matrix of transducer elements to electronically steer an acoustic beam within a 3D volume [74].

Two-dimensional US probes are used in the BAT, SonArray, and Clarity interfractional patient positioning systems, along with a position sensor (Section 4.2) to facilitate the reconstruction of individual 2D slices into a 3D volume (Section 1.1). Two-dimensional US probes can also be useful in intrafractional monitoring systems where the target anatomy is relatively stationary $[47,64]$ or when motion can be captured within a single plane [65]. Three-dimensional/fourdimensional probes are superior to 2D probes for tracking generalized 3D anatomy motion in intrafractional applications (Section 3.2).

\subsection{US Probe Tracking Techniques}

In order to image and track patient anatomy with respect to the treatment beam, US image information must be transformed to the reference frame of the LINAC. As part of this process, the position of the US probe with respect to the LINAC must be known. Potential techniques available to determine and track probe position in the frame of the linear accelerator include optical tracking, electromagnetic (EM) tracking, mechanical tracking, and X-ray tracking.

Optical tracking uses a system of cameras fixed in the LINAC frame and a set of tracked markers attached to the US probe. Spatial and temporal resolution is high and, for this reason, most US guidance systems use this modality $[47,58,61]$, but optical tracking systems are limited by lineof-sight requirements between the camera and markers. EM tracking uses an EM emitter on the probe and a detector fixed in the LINAC room. EM tracking does not necessarily require a clear optical line of sight between emitter and detector but is very susceptible to noise caused by metallic objects in the operating vicinity. Devices used to hold the US probe in place during intrafractional tracking (Section 2) can also be leveraged for tracking the probe. If the static or robotic device has sensors to measure each joint angle, the angles in combination with knowledge of the device geometry (forward kinematics) can be used to locate the probe in space. This tracking method is independent of the surrounding environment, but high accuracy can only be achieved by using very precise device manufacturing techniques and rigid materials. Our group is currently investigating the performance and tradeoffs between optical, EM, and mechanical tracking in the radiotherapy environment.

Bruder, et al. [75] investigated an approach to US probe localization utilizing the stereo X-ray cameras of the CyberKnife and X-ray markers attached to the probe (Accuray, Inc., Sunnyvale, CA). After a non-orthogonal stereo camera calibration using X-ray phantoms, various marker geometries were positioned using a 6-axis robotic arm, localized in 6-DOF using algorithms developed for marker localization, and compared with results from the CyberKnife onboard system. Mean translational error for the newly developed software package was $0.218 \mathrm{~mm}$ and rotational error was 0.076 degrees. Although spatial accuracy is high, this probe localization method would not be appropriate for continuously tracking the respiratory-induced probe motion as X-ray exposure practically limits the temporal resolution.

Table 3 provides a summary of the previously discussed probe tracking techniques. 


\section{Cureus}

\begin{tabular}{|c|c|c|c|c|}
\hline & Optical & Electromagnetic & Mechanical & X-ray \\
\hline $\begin{array}{l}\text { Typical spatial } \\
\text { resolution }\end{array}$ & $\begin{array}{l}0.2-0.4 \\
\mathrm{~mm}\end{array}$ & $0.5-0.8 \mathrm{~mm}$ & $0.1-5.0 \mathrm{~mm}$ & $0.2 \mathrm{~mm}$ \\
\hline Typical acquisition rate & $20-60 \mathrm{~Hz}$ & $20-200+H z$ & $\begin{array}{l}300-1000 \\
\mathrm{~Hz}\end{array}$ & $\begin{array}{l}<0.2 \mathrm{HZ} \text {. Lımıted by satety } \\
\text { considerations. }\end{array}$ \\
\hline Line of sight issues? & Yes & $\begin{array}{l}\text { Yes for some } \\
\text { materials }\end{array}$ & No & Yes for some materials \\
\hline Metal interference? & None & High & None & None \\
\hline lonizing radiation? & No & No & No & Yes \\
\hline
\end{tabular}

TABLE 3: Comparison of US probe tracking techniques available in radiotherapy.

\subsection{Assumptions for Speed of Sound in Tissue}

Uncorrected speed of sound discrepancies in soft tissue can result in US target localization errors up to a few millimeters. Salter, et al. [76] found speed artifact errors of $0.7 \mathrm{~mm}$ per $\mathrm{cm}$ of fat traversed in experiments conducted in a phantom. To correct for such discrepancies, Fontanarosa, et al. [77] applied a density-based speed of sound correction algorithm to a set of prostate, liver, and breast images collected from volunteers. Algorithms applied corrections to the speed of sound based on tissue densities drawn from CT scans co-registered to the simulation US scans. Results indicated prostate, liver, and breast centroid shifts of 3.6, 6, and $1.3 \mathrm{~mm}$, respectively, and liver volume changes of up to $9 \%$ when compared to uncorrected data. In later studies, a correction algorithm was applied to the scanning of a multi-modality US phantom through three different layers of liquid, with results showing differences between US and CT images smaller than the resolution of the CT scan (around $0.7 \mathrm{~mm}$ in the image plane) [78]. Additional studies by this group estimated errors in prostate location based on speed-ofsound aberration that agreed well with previously published discrepancies between US and CT scans, with corrections to prostate centroids averaging $3.1 \mathrm{~mm}$ [78]. With these discrepancies exceeding typical tissue tracking accuracies of US guidance systems previously discussed, results indicate a need to consider the speed of sound aberrations in estimating tumor location.

\subsection{Imaging Performance During Beam Delivery}

Studies examining the effect of radiation on US image quality have produced dissimilar conclusions, although all have demonstrated the feasibility of US ultrasound to track anatomical motion in real-time. Hsu, et al. [79] used an Acuson 128/XP US scanner to image stationary and moving phantoms while operating an Elekta SL25 LINAC. The experiment found the US images to be affected by a periodic noise at a frequency identical to the pulsing frequency of the treatment machine; however, this noise was found to have minimal effects on the precision of the tracking algorithm. Schlosser, et al. [58] found no spatial or temporal interference patterns in US images of a phantom acquired with a $3.5 \mathrm{MHz}$ Interson 2D singleelement probe during LINAC beam operation. Additionally, no significant difference in tracking accuracy was found between beam-off and beam-on cases (Figure 5). US imaging interference from a LINAC likely depends on the specifics of the US imaging system being used; for example, modern systems with improved shielding may better reject radio-frequency interference from 


\section{Cureus}

the LINAC.

(a)

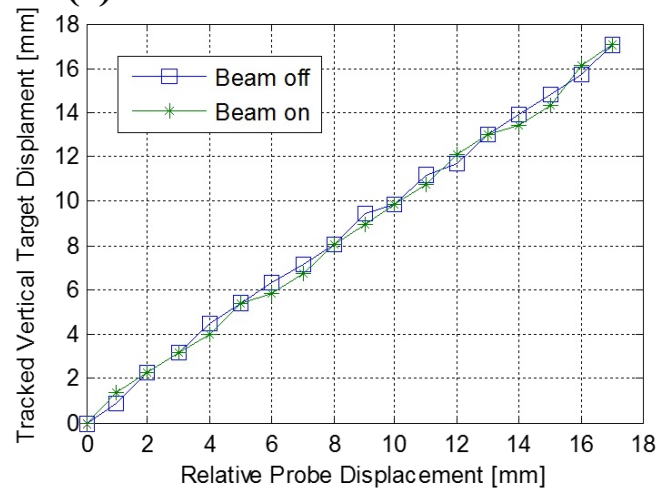

(b)

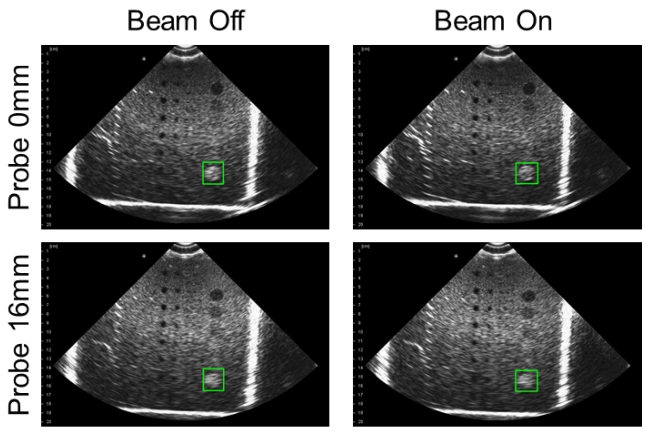

\section{FIGURE 5: Comparison of US images and tracking} performance with beam off and on, reproduced from Schlosser

\section{et al.}

Comparison of US images and tracking performance with beam off and on, reproduced from Schlosser et al. [58] (a) True object displacement versus computed displacement using crosscorrelation. (b) Tracked circular object indicated within ultrasound images at two displacement values. The square indicates the location of the tracked object based on the manually selected target template.

\subsection{Treatment Planning for Intrafractional Guidance}

Intrafractional US imaging hardware (US probe, robot, and probe tracking sensor) in the treatment field may absorb radiation and alter the dose delivered to the patient. To minimize chances of beam interference with US hardware (Figure 6), our group is collaborating with researchers at the University of Lubeck to develop US probe placement assistance software. The software analyzes the patient's CT data to suggest probe placements that achieve a clear acoustic window to the target while avoiding common beam delivery paths (Scheduled to be presented in 2015 at time of writing: Gong R, Bruder R, Schweikard A, Schlosser J, Hristov D: Augmented Reality System for Ultrasound Guided Radiation Therapy. In Computer Assisted Radiology and Surgery Conference. Barcelona, Spain; 2015). However, certain patient-specific anatomical configurations may preclude hardware placements that completely avoid beam delivery paths, and in these cases, intrafractional US hardware must be taken into account during the beam planning process. In general, this can be accomplished in two ways:

1. Avoid treatment beam positions that interfere with hardware.

2. Deliver radiation through the US image guidance hardware and account for hardware in the treatment planning process. 


\section{Cureus}
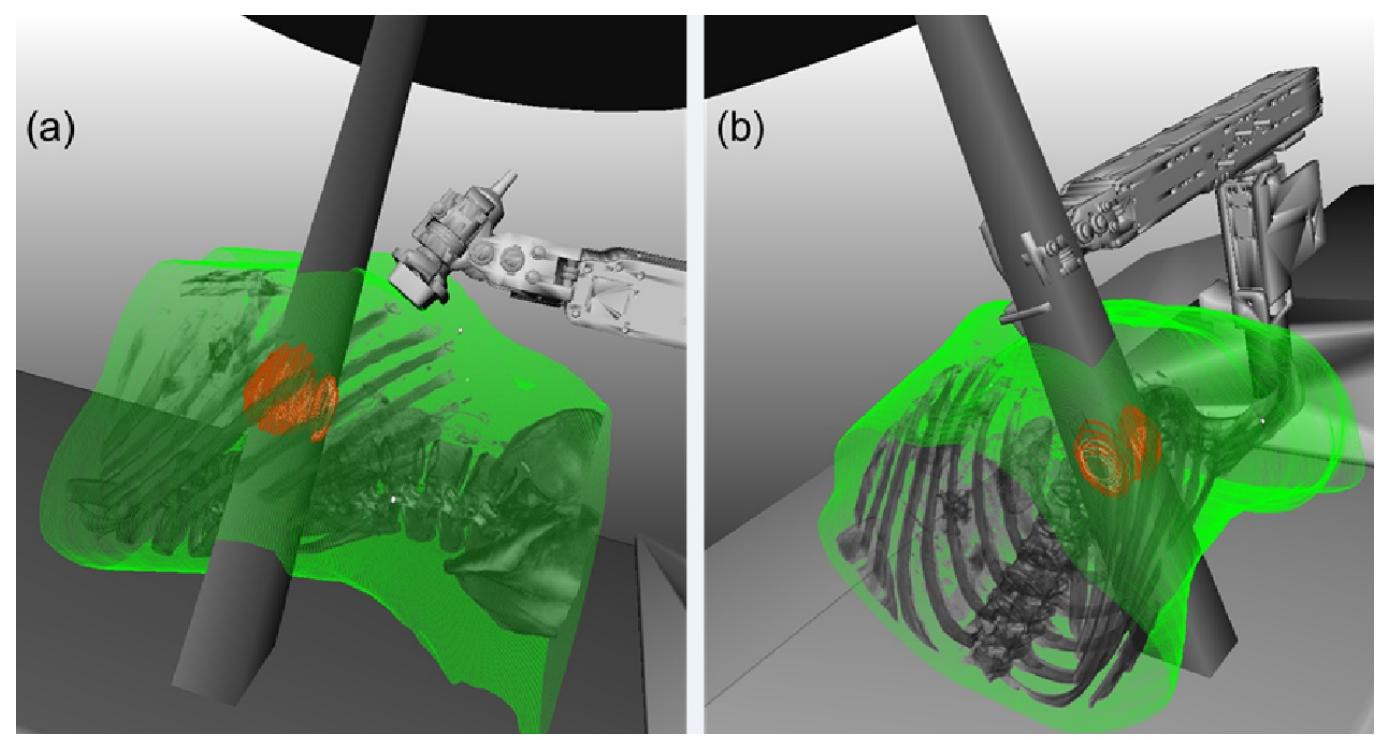

FIGURE 6: US imaging hardware configurations that (a) do not interfere and (b) interfere with certain treatment beams.

Reproduced from Schlosser[63].

Several groups have investigated the feasibility of strategy (1) by studying whether constraints on beam angles imposed by intrafractional US image guidance hardware affect the quality of treatment. Wu, et al. [81] found that avoiding the anterior-posterior beam in radiation planning, which would pass through a US probe placed in the transabdominal imaging position, resulted in a negligible effect of the transducer on dosage delivered. Schlosser, et al. [58] conducted a second feasibility study that compared a seven-beam clinical plan for a prostate IMRT patient with a seven-beam plan for the same patient that excluded a 90 degree anterior sector in order to avoid US guidance hardware in the transabdominal imaging position. No impactful difference between the plans was found (Figure 7). These two studies show that beam avoidance of US image guidance hardware is a feasible option for delivering prostate radiotherapy guided by transabdominal US imaging. 


\section{Cureus}
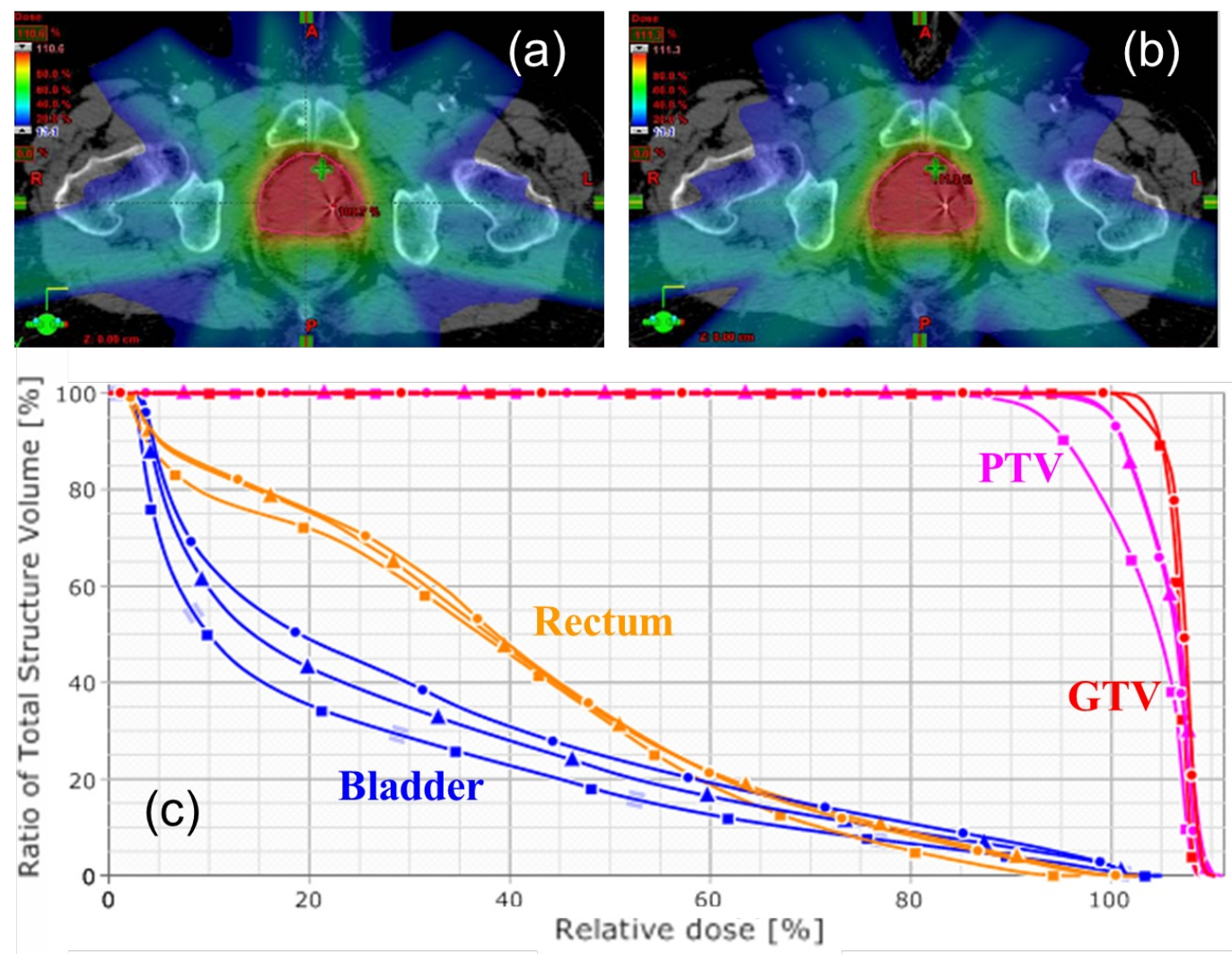

\section{FIGURE 7: Seven-beam treatment plan comparison, reproduced from Schlosser et al.}

Seven-beam treatment plan comparison, reproduced from Schlosser et al. [58] (a) Axial dose distribution for a clinical prostate IMRT plan. (b) Axial dose distribution for a reoptimized IMRT plan with restricted beam angles to avoid U.S. probe and robot links. (c) Dose-volume histograms for the clinical IMRT plan (circles), reoptimized plan (triangles), and reoptimized plan with reduced margin (squares). Note that the IMRT plan with reduced margins underdoses original planning target volume but maintains gross tumor volume coverage and improves healthy tissue sparing.

Zhong, et al. [82] examined the effect of probe orientation on liver SBRT plans that avoid an intrafractional US imaging probe. The study compared clinically accepted SBRT plans for 10 patients with liver cancer with two new plans generated for each patient that avoided irradiating the US probe. One of these two plans positioned the probe on the surface of the abdomen parallel to the patient's longitudinal axis, and the other positioned the probe vertical to the longitudinal axis. Treatment plans could not be generated for two patients with superficially located tumors for either probe orientation. For the remaining eight patients, plans were successfully generated that did not show significant differences in dosage delivery metrics. With a treatment goal of delivering 37.5 Gy to the PTV in 3 fractions, the average dose delivered to $95 \%$ of the PTV was evaluated to be $38.63 \pm 0.14 \mathrm{~Gy}$ for probe orientations parallel to the longitudinal axis; $38.48 \pm 0.31 \mathrm{~Gy}$ for probe orientations vertical to the longitudinal axis; and $38.72 \pm 0.14$ Gy for clinical SBRT plans. The authors conclude that, excluding superficial lesions, US monitoring in real-time during liver SBRT is feasible.

For delivery of radiation through US guidance hardware (strategy (2) above), Bazalova, et al. [83] accounted for the presence of US probes by developing Monte Carlo models of two Philips 
US probes: the X6-1 3D/4D transducer and the C5-2 2D transducer. Models were built based on their respective TomoTherapy images, and mass densities were assigned based on an electron density calibration phantom. Beam attenuation due to the probes was then measured in a solid water phantom for a $6 \mathrm{MV}$ and a $15 \mathrm{MV}$ beam, and the results were compared to predictions based on the Monte Carlo model. The two methods corresponded well, with over $98 \%$ of measurement points passing the $3 \% / 3 \mathrm{~mm}$ criteria for both probes and measurement depths. The extreme attenuation for probes in the upright position was found to be $25 \%$ and $31 \%$ for the C5-2 and the X6-1, respectively, for both $6 \mathrm{MV}$ and $15 \mathrm{MV}$ beams at a $10 \mathrm{~cm}$ depth. Results demonstrate the need for inclusion of a hardware model in beam treatment planning and indicate the feasibility of using Monte Carlo calculations to predict the dose delivered through traditional US probe hardware. To further mitigate potential dose interference from the US probe, our group is developing a novel radiolucent 3D/4D US image device that minimizes dose absorption through imaging hardware.

\section{Conclusions}

Recent years have seen increasing research and commercial activity toward ultrasound-based image guidance systems for radiation therapy. The BAT, Sonarray, and Clarity systems for interfractional imaging demonstrated early success in deploying US for image guidance, but technical limitations stymied the widespread adoption. The commercially available Clarity Autoscan system has moved US into the realm of intrafractional imaging for a specific application - treatment of prostate lesions. Current research aims to build out the components necessary for an intrafractional US image guidance system that integrates with existing LINACs and has the capability to image a variety of abdominal and pelvic cancers. A survey of emerging research shows great progress towards generalized intrafractional US guidance with robotically controlled US probe manipulators, robust real-time tissue tracking algorithms, and techniques for incorporating image guidance hardware into the radiotherapy treatment plan.

\section{Additional Information}

\section{Disclosures}

Conflicts of interest: In compliance with the ICMJE uniform disclosure form, all authors declare the following: Payment/services info: This material is based upon work supported by the National Science Foundation Graduate Research Fellowship under Grant No. DGE-114747. Jeff Schlosser and Dimitre Hristov were supported by NIH grant R41CA174089. Financial relationships: Jeff Schlosser, Dimitre Hristov declare(s) employment, a patent and stock/stock options from SoniTrack. Intellectual property info: Patents: Patent Application PCT/US2013/052582, Manipulation of Imaging Probe during Medical Procedure Patent Application PCT/US2014/068927, Radiotherapy Dose Assessment and Adaption Using Online Imaging. Other relationships: All authors have declared that there are no other relationships or activities that could appear to have influenced the submitted work.

\section{Acknowledgements}

This material is based upon work supported by the National Science Foundation Graduate Research Fellowship under Grant No. DGE-114747. Any opinion, findings, and conclusions or recommendations expressed in this material are those of the authors(s) and do not necessarily reflect the views of the National Science Foundation. This article contains original research conducted with human and/or animal subjects under approval from the Stanford University IRB, Development of Telerobotic System for Real-Time Soft-Tissue Image Guidance of Stereotactic Body Radiation Therapy, IRB \#20971.

\section{References}


1. Puck TT, Marcus PI: Action of x-rays on mammalian cells . J Exp Med. 1956, 103:653-666. 10.1084/jem.103.5.653

2. Fertil B, Reydellet I, Deschavanne PJ: A benchmark of cell survival models using survival curves for human cells after completion of repair of potentially lethal damage. Radiat Res. 1994, 138:61-69.

3. Timmerman RD: An overview of hypofractionation and introduction to this issue of seminars in radiation oncology. Semin Radiat Oncol. 2008, 18:215-222.

10.1016/j.semradonc.2008.04.001

4. Lo SS, Fakiris AJ, Chang EL, Mayr NA, Wang JZ, Papiez L, Teh BS, McGarry RC, Cardenes HR, Timmerman RD: Stereotactic body radiation therapy: a novel treatment modality . Nat Rev Clin Oncol. 2010, 7:44-54. 10.1038/nrclinonc.2009.188

5. Papiez L, Timmerman R: Hypofractionation in radiation therapy and its impact . Med Phys. 2008, 35:112-118. 10.1118/1.2816228

6. Minn AY, Schellenberg D, Maxim P, Suh Y, McKenna S, Cox B, Dieterich S, Xing L, Graves E, Goodman KA, Chang D, Koong AC: Pancreatic tumor motion on a single planning 4D-CT does not correlate with intrafraction tumor motion during treatment. Am J Clin Oncol. 2009, 32:364-368. 10.1097/COC.0b013e31818da9e0

7. Feng M, Balter JM, Normolle D, Adusumilli S, Cao Y, Chenevert TL, Ben-Josef E: Characterization of pancreatic tumor motion using cine MRI: surrogates for tumor position should be used with caution. Int J Radiat Oncol Biol Phys. 2009, 74:884-891. 10.1016/j.ijrobp.2009.02.003

8. Buyyounouski MK, Price RA Jr, Harris EE, Miller R, Tomé W, Schefter T, Parsai EI, Konski AA, Wallner PE: Stereotactic body radiotherapy for primary management of early-stage, low- to intermediate-risk prostate cancer: report of the American Society for Therapeutic Radiology and Oncology Emerging Technology Committee. Int J Radiat Oncol Biol Phys. 2010, 76:1297304. 10.1016/j.ijrobp.2009.09.078

9. Pawlowski JM, Yang ES, Malcolm AW, Coffey CW, Ding GX: Reduction of dose delivered to organs at risk in prostate cancer patients via image-guided radiation therapy. Int J Radiat Oncol Biol Phys. 2010, 76:924-934. 10.1016/j.ijrobp.2009.06.068

10. Li JS, Jin L, Pollack A, Horwitz EM, Buyyounouski MK, Price Jr RA, Ma C-M: Gains from realtime tracking of prostate motion during external beam radiation therapy. Int J Radiat Oncol Biol Phys. 2009, 75:1613-1620. 10.1016/j.ijrobp.2009.05.022

11. Gierga DP, Chen GTY, Kung JH, Betke M, Lombardi J, Willett CG: Quantification of respiration-induced abdominal tumor motion and its impact on IMRT dose distributions. Int J Radiat Oncol Biol Phys. 2004, 58:1584-1595. 10.1016/j.ijrobp.2003.09.077

12. Wu QJ, Thongphiew D, Wang Z, Chankong V, Yin FF: The impact of respiratory motion and treatment technique on stereotactic body radiation therapy for liver cancer. Med Phys. 2008, 35:1440-1451. 10.1118/1.2839095

13. Kitamura K, Shirato H, Seppenwoolde Y, Onimaru R, Oda M, Fujita K, Shimizu S, Shinohara N, Harabayashi T, Miyasaka K: Three-dimensional intrafractional movement of prostate measured during real-time tumor-tracking radiotherapy in supine and prone treatment positions. Int J Radiat Oncol Biol Phys. 2002, 53:1117-1123. 10.1016/S0360-3016(02)02882-1

14. Chung PW, Haycocks T, Brown T, Cambridge Z, Kelly V, Alasti H, Jaffray DA, Catton CN: Online aSi portal imaging of implanted fiducial markers for the reduction of interfraction error during conformal radiotherapy of prostate carcinoma. Int J Radiat Oncol Biol Phys. 2004, 60:329-334. 10.1016/j.ijrobp.2004.03.038

15. Willoughby TR, Forbes AR, Buchholz D, Langen KM, Wagner TH, Zeidan OA, Kupelian PA, Meeks SL: Evaluation of an infrared camera and X-ray system using implanted fiducials in patients with lung tumors for gated radiation therapy. Int J Radiat Oncol Biol Phys. 2006, 66:568-575. 10.1016/j.ijrobp.2006.05.029

16. Sorcini B, Tilikidis A: Clinical application of image-guided radiotherapy, IGRT (on the Varian OBI platform). Cancer Radiother. 2006, 10:252-257. 10.1016/j.canrad.2006.05.012

17. Nichol AM, Brock KK, Lockwood GA, Moseley DJ, Rosewall T, Warde PR, Catton CN, Jaffray DA: A magnetic resonance imaging study of prostate deformation relative to implanted gold fiducial markers. Int J Radiat Oncol Biol Phys. 2007, 67:48-56. 10.1016/j.ijrobp.2006.08.021

18. Shirato H, Harada T, Harabayashi T, Hida K, Endo H, Kitamura K, Onimaru R, Yamazaki K, Kurauchi N, Shimizu T, Shinohara N, Matsushita M, Dosaka-Akita H, Miyasaka K: Feasibility of insertion/implantation of 2.0-mm-diameter gold internal fiducial markers for precise setup 
and real-time tumor tracking in radiotherapy. Int J Radiat Oncol Biol Phys. 2003, 56:240-247. 10.1016/S0360-3016(03)00076-2

19. Langenhuijsen JF, van Lin EN, Kiemeney LA, van der Vight LP, McColl GM, Visser AG, Witjes JA: Ultrasound-guided transrectal implantation of gold markers for prostate localization during external beam radiotherapy: complication rate and risk factors. Int J Radiat Oncol Biol Phys. 2007, 69:671-676. 10.1016/j.ijrobp.2007.04.009

20. Vandenbroucke F, Vinh-Hung V, Craggs B, Buls N, de Mey J: Image-guided marker placement in liver tumors for stereotactic radiotherapy: technique and safety. J Comput Assist Tomogr. 2010, 34:367-371. 10.1097/RCT.0b013e3181cda063

21. Wunderink W, Méndez Romero A, Seppenwoolde Y, de Boer H, Levendag P, Heijmen B: Potentials and limitations of guiding liver stereotactic body radiation therapy set-up on liverimplanted fiducial markers. Int J Radiat Oncol Biol Phys. 2010, 77:1573-1583.

10.1016/j.ijrobp.2009.10.040

22. Henry AM, Wilkinson C, Wylie JP, Logue JP, Price P, Khoo VS: Trans-perineal implantation of radio-opaque treatment verification markers into the prostate: an assessment of procedure related morbidity, patient acceptability and accuracy. Radiother Oncol. 2004, 73:57-59. 10.1016/j.radonc.2004.08.007

23. Kupelian PA, Willoughby TR, Meeks SL, Forbes A, Wagner T, Maach M, Langen KM: Intraprostatic fiducials for localization of the prostate gland: monitoring intermarker distances during radiation therapy to test for marker stability. Int J Radiat Oncol Biol Phys. 2005, 62:1291-1296. 10.1016/j.ijrobp.2005.01.005

24. Ghilezan MJ, Jaffray DA, Siewerdsen JH, Van Herk M, Shetty A, Sharpe MB, Zafar Jafri S, Vicini FA, Matter RC, Brabbins DS, Martinez AA: Prostate gland motion assessed with cine-magnetic resonance imaging (cine-MRI). Int J Radiat Oncol Biol Phys. 2005, 62:406-417.

10.1016/j.ijrobp.2003.10.017

25. Jaffray DA: Kilovoltage volumetric imaging in the treatment room . Front Radiat Ther Oncol. 2007, 40:116-131. 10.1159/000106031

26. Kupelian P, Willoughby T, Mahadevan A, Djemil T, Weinstein G, Jani S, Enke C, Solberg T, Flores N, Liu D, Beyer D, Levine L: Multi-institutional clinical experience with the Calypso System in localization and continuous, real-time monitoring of the prostate gland during external radiotherapy. Int J Radiat Oncol Biol Phys. 2007, 67:1088-1098.

10.1016/j.ijrobp.2006.10.026

27. Willoughby TR, Kupelian PA, Pouliot J, Shinohara K, Aubin M, Roach M, 3rd, Skrumeda LL, Balter JM, Litzenberg DW, Hadley SW, Wei JT, Sandler HM: Target localization and real-time tracking using the Calypso 4D localization system in patients with localized prostate cancer. Int J Radiat Oncol Biol Phys. 2006, 65:528-534. 10.1016/j.ijrobp.2006.01.050

28. Litzenberg DW, Balter JM, Hadley SW, Sandler HM, Willoughby TR, Kupelian PA, Levine L: Influence of intrafraction motion on margins for prostate radiotherapy . Int J Radiat Oncol Biol Phys. 2006, 65:548-553. 10.1016/j.ijrobp.2005.12.033

29. Lagendijk JJ, Raaymakers BW, Raaijmakers AJ, Overweg J, Brown KJ, Kerkhof EM, van der Put RW, Hårdemark B, van Vulpen M, van der Heide UA: MRI/linac integration. Radiother Oncol. 2008, 86:25-29. 10.1016/j.radonc.2007.10.034

30. Fallone BG, Murray B, Rathee S, Stanescu T, Steciw S, Vidakovic S, Blosser E, Tymofichuk D: First MR images obtained during megavoltage photon irradiation from a prototype integrated linac-MR system. Med Phys. 2009, 36:2084-2088. 10.1118/1.3125662

31. Fan Q, Nanduri A, Mazin S, Zhu L: Emission guided radiation therapy for lung and prostate cancers: A feasibility study on a digital patient. Med Phys. 2012, 39:7140-7152. 10.1118/1.4761951

32. Wei Z, Wan G, Gardi L, Mills G, Downey D, Fenster A: Robot-assisted 3D-TRUS guided prostate brachytherapy: system integration and validation. Med Phys. 2004, 31:539-548. $10.1118 / 1.1645680$

33. Stromberg J, Martinez A, Gonzalez J, Edmundson G, Ohanian N, Vicini F, Hollander J, Gustafson G, Spencer W, Yan D, Brabbins D: Ultrasound-guided high dose rate conformal brachytherapy boost in prostate cancer: Treatment description and preliminary results of a phase I. Int J Radiat Oncol Biol Phys. 1995, 33:161-171. 10.1016/0360-3016(95)00035-W

34. Youk JH, Kim E-K, Kim MJ, Oh KK: Sonographically guided 14-gauge core needle biopsy of breast masses: a review of 2,420 cases with long-term follow-up. AJR Am J Roentgenol. 2008, 190:202-207. 10.2214/AJR.07.2419 
35. Molloy JA, Chan G, Markovic A, McNeeley S, Pfeiffer D, Salter B, Tome WA; AAPM Task Group 154: Quality assurance of US-guided external beam radiotherapy for prostate cancer: Report of AAPM Task Group 154. Med Phys. 2011, 38:857-871. 10.1118/1.3531674

36. Lattanzi J, McNeeley S, Donnelly S, Palacio E, Hanlon A, Schultheiss TE, Hanks GE: Ultrasound-based stereotactic guidance in prostate cancer--quantification of organ motion and set-up errors in external beam radiation therapy. Comput Aided Surg. 2000, 5:289-295. 10.3109/10929080009148896

37. Trichter F, Ennis RD: Prostate localization using transabdominal ultrasound imaging . Int J Radiat Oncol Biol Phys. Physics, 56:1225-1233. 10.1016/S0360-3016(03)00269-4

38. Little DJ, Dong L, Levy LB, Chandra A, Kuban DA: Use of portal images and BAT ultrasonography to measure setup error and organ motion for prostate IMRT: implications for treatment margins. Int J Radiat Oncol Biol Phys. 2003, 56:1218-1224. 10.1016/S03603016(03)00290-6

39. Boda-Heggemann J, Köhler FM, Küpper B, Wolff D, Wertz H, Mai S, Hesser J, Lohr F, Wenz F: Accuracy of ultrasound-based (BAT) prostate-repositioning: a three-dimensional on-line fiducial-based assessment with cone-beam computed tomography. Int J Radiat Oncol Biol Phys. 2008, 70:1247-1255. 10.1016/j.ijrobp.2007.12.003

40. Hatcher DC: Operational principles for cone-beam computed tomography. J Am Dent Assoc. 2010, 141:3S-6S. 10.14219/jada.archive.2010.0359

41. Langen KM, Pouliot J, Anezinos C, Aubin M, Gottschalk AR, Hsu IC, Lowther D, Liu YM, Shinohara K, Verhey LJ, Weinberg V, Roach M 3rd: Evaluation of ultrasound-based prostate localization for image-guided radiotherapy. Int J Radiat Oncol Biol Phys. 2003, 57:635-644. 10.1016/S0360-3016(03)00633-3

42. Van den Heuvel F, Powell T, Seppi E, Littrupp P, Khan M, Wang Y, Forman JD: Independent verification of ultrasound based image-guided radiation treatment, using electronic portal imaging and implanted gold markers. Med Phys. 2003, 30:2878-2887. 10.1118/1.1617354

43. Peignaux K, Truc G, Barillot I, Ammor A, Naudy S, Créhange G, Maingon P: Clinical assessment of the use of the Sonarray system for daily prostate localization. Radiother Oncol. 2006, 81:176-178. 10.1016/j.radonc.2006.08.027

44. Scarbrough TJ, Golden NM, Ting JY, Fuller CD, Wong A, Kupelian PA, Thomas CR Jr: Comparison of ultrasound and implanted seed marker prostate localization methods: Implications for image-guided radiotherapy. Int J Radiat Oncol Biol Phys. 2006, 65:378-387. 10.1016/j.ijrobp.2006.01.008

45. Molloy JA, Srivastava S, Schneider BF: A method to compare supra-pubic ultrasound and CT images of the prostate: technique and early clinical results. Med Phys. 2004, 31:433-442. $10.1118 / 1.1644515$

46. Cury FL, Shenouda G, Souhami L, Duclos M, Faria SL, David M, Verhaegen F, Corns R, Falco T: Ultrasound-based image guided radiotherapy for prostate cancer: comparison of crossmodality and intramodality methods for daily localization during external beam radiotherapy. Int J Radiat Oncol Biol Phys. 2006, 66:1562-1567. 10.1016/j.ijrobp.2006.07.1375

47. Lachaine M, Falco T: Intrafractional prostate motion management with the Clarity Autoscan system. Med Phys Int. 2013, 1:72-80.

48. Bloemen-van Gurp E, van der Meer S, Hendry J, Buijsen J, Visser P, Fontanarosa D, Lachaine M, Lammering G, Verhaegen F: Active breathing control in combination with ultrasound imaging: a feasibility study of image guidance in stereotactic body radiation therapy of liver lesions. Int J Radiat Oncol Biol Phys. 2013, 85:1096-102. 10.1016/j.ijrobp.2012.08.016

49. Wong P, Muanza T, Reynard E, Robert K, Barker J, Sultanem K: Use of three-dimensional ultrasound in the detection of breast tumor bed displacement during radiotherapy. Int J Radiat Oncol Biol Phys. 2011, 79:39-45. 10.1016/j.ijrobp.2009.10.023

50. Robinson D, Liu D, Steciw S, Field C, Daly H, Saibishkumar EP, Fallone G, Parliament M, Amanie J: An evaluation of the Clarity 3D ultrasound system for prostate localization . J Appl Clin Med Phys. 2012, 13:3753. 10.1120/jacmp.v13i4.3753

51. Fargier-Voiron M, Presles B, Pommier P, Rit S, Munoz A, Liebgott H, Sarrut D, Biston MC: Impact of probe pressure variability on prostate localization for ultrasound-based imageguided radiotherapy. Radiother Oncol. 2014, 111:132-137. 10.1016/j.radonc.2014.02.008

52. Serago CF, Chungbin SJ, Buskirk SJ, Ezzell GA, Collie AC, Vora SA: Initial experience with ultrasound localization for positioning prostate cancer patients for external beam radiotherapy. Int J Radiat Oncol Biol Phys. 2002, 53:1130-1138. 10.1016/S0360- 


\section{6(02)02826-2}

53. Lediju Bell MA, Sen HT, Iordachita I, Kazanzides P, Wong J: In vivo reproducibility of robotic probe placement for a novel ultrasound-guided radiation therapy system. J Med Imag. 2014, 1:025001-9. 10.1117/1.JMI.1.2.025001

54. Orton NP, Jaradat HA, Tomé WA: Clinical assessment of three-dimensional ultrasound prostate localization for external beam radiotherapy. Med Phys. 2006, 33:4710-4717. 10.1118/1.2388153

55. Arbeille P, Ruiz J, Ayoub J, Vieyres P, Porcher M, Boulay J, Moreau V, Poisson G: The robot and the satellite for tele-operating echographic examination in Earth isolated sites, or onboard ISS. J Gravit Physiol. 2004, 11:P233-4.

56. Masuda K, Tateishi N, Kimura E, Ishihara K: Development of a tele-echography system by using an echographic diagnosis robot. Igaku Butsuri. 2003, 23:24-29.

10.11323/jimp2000.23.1_24

57. Martinelli T, Bosson JL, Bressollette L, Pelissier F, Boidard E, Troccaz J, Cinquin P: Robotbased tele-echography: clinical evaluation of the TER system in abdominal aortic exploration. J Ultrasound Med. 2007, 26:1611-1616.

58. Schlosser J, Salisbury K, Hristov D: Telerobotic system concept for real-time soft-tissue imaging during radiotherapy beam delivery. Med Phys. 2010, 37:6357-6367.

10.1118/1.3515457

59. Force and Image Adaptive Strategies for Robotised Placement of 4D Ultrasound Probes . (2013). Accessed: June 12, 2015: https://www.rob.uni-luebeck.de/index.php? id=386\&author $=0: 2571 \& \mathrm{~L}=1$.

60. Robotized 4D ultrasound for cardiac image-guided radiation therapy . (2012). Accessed: June 12, 2015: https://www.rob.uni-luebeck.de/index.php?id=386\&author=0:2572 \&L=1.

61. Sen HT, Bell MA, Iordachita I, Wong J, Kazanzides P: A cooperatively controlled robot for ultrasound monitoring of radiation therapy. 2013 IEEE/RSJ International Conference on Intelligent Robots and Systems (IROS). 2013, 3071-3076.

http://ieeexplore.ieee.org/xpl/login.jsp? tp=\&arnumber=6696791 \&url=http\%3A\%2F\%2Fieeexplore.ieee.org\%2Fxpls\%2Fabs_all.j.... 10.1109/IROS.2013.6696791

62. Bell ML, Sen HT, Kazanzides P, Iordachita I, Forbang RT, Boctor E, Lachaine M, Wong J: SU-EU- 13: Repeatability of robotic placement of ultrasound probes for an integrated US-CT approach to image-guided radiotherapy. Med Phys. 2013, 40:376. 10.1118/1.4815166

63. Robotic Ultrasound Image Guidance for Radiation Therapy. (2013). Accessed: June 12, 2015: http://searchworks.stanford.edu/view/9957587.

64. Schlosser J, Salisbury K, Hristov D: Online image-based monitoring of soft-tissue displacements for radiation therapy of the prostate. Int J Radiat Oncol Biol Phys. 2012, 83:1633-40. 10.1016/j.ijrobp.2011.10.049

65. Schlosser J, Salisbury K, Hristov D: Image-based approach to respiratory gating for liver radiotherapy using a telerobotic ultrasound system. Int J Radiat Oncol Biol Phys. 2011, 81:S122. 10.1016/j.ijrobp.2011.06.250

66. Harris EJ, Miller NR, Bamber JC, Symonds-Tayler JR, Evans PM: Speckle tracking in a phantom and feature-based tracking in liver in the presence of respiratory motion using 4D ultrasound. Phys Med Biol. 2010, 55:3363-80. 10.1088/0031-9155/55/12/007

67. Bell MA, Byram BC, Harris EJ, Evans PM, Bamber JC: In vivo liver tracking with a high volume rate 4D ultrasound scanner and a 2D matrix array probe. Phys Med Biol. 2012, 57:1359-74. 10.1088/0031-9155/57/5/1359

68. O'Shea TP, Garcia LJ, Rosser KE, Harris EJ, Evans PM, Bamber JC: 4D ultrasound speckle tracking of intra-fraction prostate motion: a phantom-based comparison with $\mathrm{x}$-ray fiducial tracking using CyberKnife. Phys Med Biol. 2014, 59:1701-20. 10.1088/0031-9155/59/7/1701

69. Abramowitz MC, Bossart E, Flook R, Wu X, Brooks R, Lachaine M, Lathuiliere F, Wu X, Pollack A: Noninvasive real-time prostate tracking using a transperineal ultrasound approach . Int J Radiat Oncol Biol Phys. 2012, 84:S133. 10.1016/j.ijrobp.2012.07.145

70. Bruder R, Ernst F, Schlaefer A, Schweikard A: Real-time PV: Tracking in 3D ultrasound of the beating heart. Med Phys. 2009, 36:2804. 10.1118/1.3182643

71. Kubota Y, Matsumura A, Fukahori M, Minohara S, Yasuda S, Nagahashi H: A new method for tracking organ motion on diagnostic ultrasound images. Med Phys. 2014, 41:092901.

$10.1118 / 1.4892065$ 
72. Wild JJ: The use of ultrasonic pulses for the measurement of biologic tissues and the detection of tissue density changes. Surgery. 1950, 27:183-188.

73. Smith WL, Fenster A: Optimum scan spacing for three-dimensional ultrasound by speckle statistics. Ultrasound Med Biol. 2000, 26:551-562. 10.1016/S0301-5629(99)00162-3

74. Stetten G, Tamburo R: Real-time three-dimensional ultrasound methods for shape analysis and visualization. Methods. 2001, 25:221-230. 10.1006/meth.2001.1236

75. Bruder R, Ipsen S, Jauer P, Ernst F, Blanck O, Schweikard A: MO-D-144-02: Ultrasound transducer localization using the CyberKnife's X-Ray system. Med Phys. 2013, 40:405. http://scitation.aip.org/content/aapm/journal/medphys/40/6/10.1118/1.4815272. 10.1118/1.4815272

76. Salter BJ, Wang B, Szegedi MW, Rassiah-Szegedi P, Shrieve DC, Cheng R, Fuss M: Evaluation of alignment error due to a speed artifact in stereotactic ultrasound image guidance. Phys Med Biol. 2008, 53:N437-45. 10.1088/0031-9155/53/23/N03

77. Fontanarosa D, van der Meer S, Bloemen-van Gurp E, Stroian G, Verhaegen F: Magnitude of speed of sound aberration corrections for ultrasound image guided radiotherapy for prostate and other anatomical sites. Med Phys. 2012, 39:5286-5292. 10.1118/1.4737571

78. Fontanarosa D, Pesente S, Pascoli F, Ermacora D, Rumeileh IA, Verhaegen F: A speed of sound aberration correction algorithm for curvilinear ultrasound transducers in ultrasound-based image-guided radiotherapy. Phys Med Biol. 2013, 58:1341-1360. 10.1088/00319155/58/5/1341

79. Hsu A, Miller NR, Evans PM, Bamber JC, Webb S: Feasibility of using ultrasound for real-time tracking during radiotherapy. Med Phys. 2005, 32:1500-1512. 10.1118/1.1915934

80. Bruder R, Ernst F, Stender B, Richter L, Schweikard A: SU-D- 220-02: Optimal Transducer Position for 4D Ultrasound Guidance in Cardiac IGRT. Medical Physics. 2011, 38:3390. http://scitation.aip.org/content/aapm/journal/medphys/38/6/10.1118/1.3611550. $10.1118 / 1.3611550$

81. Wu J, Dandekar O, Nazareth D, Lei P, D'Souza W, Shekhar R: Effect of ultrasound probe on dose delivery during real-time ultrasound-guided tumor tracking. Conf Proc IEEE Eng Med Biol Soc. 2006, 1:3799-3802. 10.1109/IEMBS.2006.260076

82. Zhong Y, Stephans K, Qi P, Yu N, Wong J, Xia P: Assessing feasibility of real-time ultrasound monitoring in stereotactic body radiotherapy of liver tumors. Technol Cancer Res Treat. 2013, 12:243-250. 10.7785/tcrt.2012.500323

83. Hristov D, Schlosser J, Chen J, Bazalova M: SU-EJ- 205: Monte Carlo modeling of ultrasound probes for real-time ultrasound image-guided radiotherapy. Med Phys. 2014, 41:204.

$10.1118 / 1.4888258$ 